\title{
Angioplasty balloon occlusion of internal thoracic artery in redo surgery in patients with coronary artery bypass operations
}

\author{
J. M. Grinda, MD, C. P. Latremouille, MD, PhD, N. D'Attellis, MD, A. Berrebi, MD, and J. N. Fabiani, MD, \\ Paris, France
}

$\mathrm{R}$ edo cardiac procedures have become increasingly common practice in most cardiac centers. During such redo operations, the presence and control of a patent internal thoracic artery-left anterior descending (ITA-LAD) graft during dissection of the cardiac mass remains a problem. Hypothermic fibrillation without aortic crossclamping can be a useful technique. Surgeons who are reluctant to use this technique usually clamp the ITA graft during aortic crossclamping to ensure optimal myocardial arrest and protection. Surgical dissection, control, and clamping of an ITA graft involve inherent risk, which may affect outcome. ${ }^{1}$ Endoluminal control of a patent ITA-LAD graft is an interesting alternative to other conventional median sternotomy approaches.

\section{Clinical Summaries History}

PATIENT 1. A 72-year-old man was referred in March 1999 for a left atrial tumor 4 years after coronary artery bypass grafting (CABG) with a single left ITA (LITA)-LAD graft performed during the preoperative work-up of an abdominal aortic aneurysm. Recovery from the 2 operations was uneventful. The left atrial tumor was discovered by echocardiography during postoperative follow-up. A spiral computed tomographic scan provided a precise image of the tumor; it had a maximum diameter of $26 \mathrm{~mm}$ and was homogeneous, noncalcified, and attached by a pedicle to the atrial septum. To avoid the risks associated with dissection of the LITA-LAD graft, we decided to use endoluminal control of the graft and a surgical approach by a right thoracotomy (Figure 1).

PATIENT 2. A 72-year-old man was referred in July 1999 for aortic valve replacement 5 years after undergoing 3 CABGs (LITALAD and 2 saphenous grafts on the right coronary and the marginal arteries). Preoperative coronary angiography showed that all the grafts were patent. We chose to use a ministernotomy and endoluminal control of the LITA-LAD graft (Figure 2).

From the Department of Cardiovascular Surgery, Hôpital Européen Georges Pompidou (HEGP), Paris, France.

Received for publication Sept 25, 2000; accepted for publication Oct 24, 2000.

Address for reprints: Jean-Michel Grinda, MD, Department of Cardiovascular Surgery, Hôpital Européen Georges Pompidou (HEGP), 20, rue Leblanc, 75908 Paris, Cedex 15, France (E-mail: jean_michel.grinda@egp.ap_hop_paris.fr).

J Thorac Cardiovasc Surg 2001;122:182-3

Copyright $\odot 2001$ by The American Association for Thoracic Surgery $0022-5223 / 2001 \$ 35.00+0 \quad \mathbf{1 2 / 5 4 / 1 1 3 0 1 5}$

doi:10.1067/mtc.2001.113015

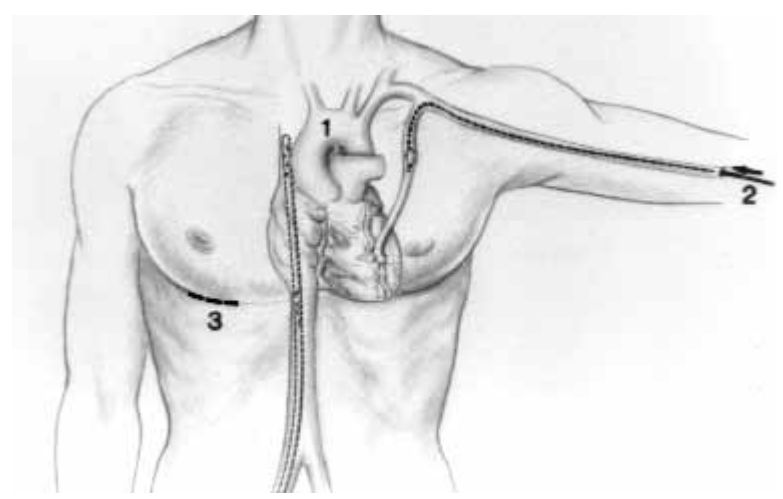

Figure 1. Proposed right anterolateral thoracotomy, the doublestage venous cannula, and control of the LITA graft by angioplasty balloon for myxoma removal.

Angioplasty balloon positioning and inflation test. Before the operation, the patients were transferred to the cardiac catheterization laboratory. Coronary angiography was performed via the left brachial artery. Selective catheterization of the LITA graft demonstrated perfect patency. An angioplasty balloon (Gemini 2.5 $\mathrm{mm} / 15 \mathrm{~mm}$; ACS Guidant, Indianapolis, Ind) was positioned in the median portion of the graft via a wire (BMW 0.014; ACS Guidant), which was left in the coronary network. The graft was transiently occluded by inflating the balloon to $4 \mathrm{~atm}$. Both the balloon and guidewire were left in place under full heparinization and the patient was transferred to the operating room.

\section{Surgical Procedures}

PATIENT 1. The patient was positioned in the decubitus position. The right side was raised $45^{\circ}$ with the left arm accessible. Surgery was performed through a right anterolateral thoracotomy in the fourth intercostal space. Cardiopulmonary bypass (CPB) was initiated between a double-stage venous cannula (Carpentier bicaval femoral cannula; DLP, Inc, Grand Rapids, Mich; Medtronic, Inc, Minneapolis, Minn) inserted through the right femoral vein and a right femoral arterial cannula. The venae cavae were snared. Simultaneous to aortic crossclamping, the LITA-LAD graft flow was interrupted by angioplasty balloon inflation and cardioplegic solution was injected via the aortic root. The tumor was then excised via a transseptal approach (Figure 3). Total CPB time was 32 minutes, and both aortic crossclamp and LITA occlusion times were 21 minutes, with spontaneous recovery of cardiac function. The postoperative course was uneventful, with no increase in cardiac enzymes or modifications of the electrocardiogram. 


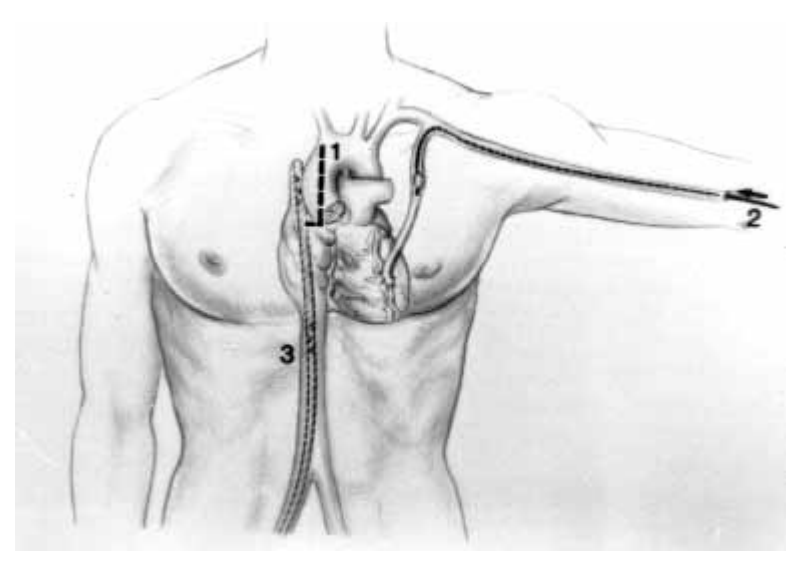

Figure 2. Proposed J-shaped ministernotomy and control of the LITA graft by angioplasty balloon for aortic valve replacement.

Pathologic examination confirmed the diagnosis of myxoma. At 18 months' follow-up the patient is doing well.

PATIENT 2. The patient was positioned in the dorsal decubitus position, with the left arm accessible. The operation was performed through a superior longitudinal ministernotomy extending to the fourth intercostal space (ministernotomy in a $\mathrm{J}$ shape). CPB was instituted between a double-stage venous cannula (Carpentier bicaval femoral cannula; DLP and Medtronic) inserted through the right femoral vein and an ascending aortic cannula. Only the ascending aorta was dissected. Simultaneous to aortic balloon inflation, cardioplegic solution was injected via the aortic root. The aorta was opened so as to not injure the proximal anastomosis of the saphenous graft. A vent was directly positioned in the left ventricle through the aortic orifice. The aortic valve was resected and a double-leaflet mechanical prosthesis was inserted. Total CPB time was 44 minutes, and both aortic crossclamp and LITA occlusion times were 35 minutes, with spontaneous recovery of cardiac function. The postoperative course was uneventful, with no increase in cardiac enzymes or modifications of the electrocardiogram. At 12 months' follow-up the patient is doing well.

\section{Discussion}

A patent ITA graft is undoubtedly a problem in the event of redo cardiac surgery. Surgical control of patent ITA grafts is usual when only the posterolateral wall must be revascularized during redo CABG. Nevertheless, surgical control of the patent ITA graft should be avoided during redo surgery for valvular or tumoral disease, more so than when other conventional median sternotomy approaches can be used.

We routinely perform operations on the atrioventricular valves or atrial septum through a right anterolateral thoracotomy ${ }^{2}$ and aortic valve replacement as well as redo aortic valve replacement through a J-shaped ministernotomy. The use of endoluminal control of a patent LITA-LAD graft further extends the indications of

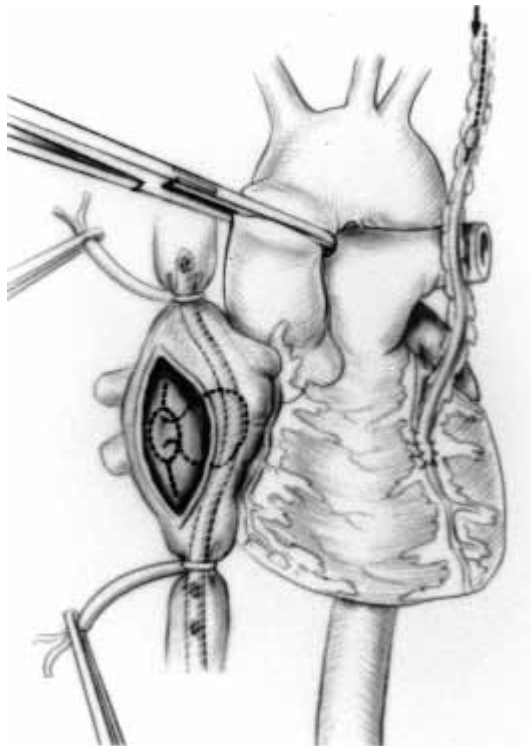

Figure 3. Proposed endoluminal occlusion of the LITA simultaneous to aortic crossclamping and myxoma removal through a transseptal approach.

this surgical approach to patients who have previously undergone a bypass procedure with a LITA-LAD graft.

Most reports concerning angioplasty and ITA grafts focus on dilatation of anastomotic sites or the graft itself or else on accessibility to the coronary network via the graft. ${ }^{3,4}$ Little information is available concerning the potential risks of endothelial damage and potential long-term consequence, for example, late stenosis or occlusion, that can occur with prolonged endoluminal occlusion of an ITA graft. The choice of size of the angioplasty balloon was based on the size of the ITA graft, and previous inflation tests permitted the determination of the minimal amount of inflation ensuring interruption of blood flow through the graft without excessive pressure on the intima. In these conditions, the risk of endoluminal occlusion appears comparable with that of external graft clamping and the preferred endoluminal control is, in our opinion, justified by the advantages described herein.

\section{References}

1. He G-W, Acuff TE, Ryan WH, He Y-H, Mack MJ. Determinants of operative mortality in reoperative coronary artery bypass grafting. $J$ Thorac Cardiovasc Surg. 1995;110:971-8.

2. Grinda JM, Folliguet TA, Dervanian P, Macé L, Legault B, Neveux JY, Right anterolateral thoracotomy for repair of atrial septal defect. Ann Thorac Surg. 1996;62:175-8.

3. Shimshak TM, Giorgi LV, Johnson LL, et al. Application of percutaneous coronary angioplasty to the internal mammary artery graft. $J \mathrm{Am}$ Coll Cardiol. 1988;12:205-14.

4. Hearne SE, Davidson CJ, Zidar JP, Phillips HR, Stack RS, Sketch MH Jr. Internal mammary artery graft angioplasty: acute and long-term outcome. Cathet Cardiovasc Diagn. 1998;44:153-6. 